\section{Evans syndrome and antibody deficiency: an atypical presentation of chromosome 22q11.2 deletion syndrome}

\author{
Gloria Colarusso,' Eleonora Gambineri, ${ }^{1}$ \\ Elisabetta Lapi, ${ }^{2}$ Tommaso Casini, ${ }^{3}$ \\ Fabio Tucci, ${ }^{3}$ Francesca Lippi, \\ Chiara Azzari' \\ 'Paediatric Immunology Unit, ${ }^{2}$ Genetics \\ and Molecular Medicine Unit, ${ }^{3}$ Paediatric \\ Haematology Unit, University of \\ Florence, Anna Meyer Children's \\ Hospital, Florence, Italy
}

\begin{abstract}
We report a case of an 8-year-old male patient with Evans syndrome and severe hypogammaglobulinemia, subsequently in whom the $22 q 11.2$ deletion syndrome (22q11.2 DS) was diagnosed. No other clinical sign of 22q11.2 DS was present with the exception of slight facial dysmorphism. The case is of particular interest because it suggests the need to research chromosome 22q11.2 deletion in patients who present with autoimmune cytopenia and peculiar facial abnormalities, which could be an atypical presentation of an incomplete form of 22q11.2 DS.
\end{abstract}

\section{Introduction}

Chromosome 22q11.2 deletion syndrome (22q11.2 DS) is considered the most common human deletion syndrome with an estimated incidence of 1:4000 live births. ${ }^{1}$ More than $90 \%$ of the patients are hemizygous for a $1.5-3 \mathrm{Mb}$ deletion within the $22 q 11.2$ region. ${ }^{2}$ The clin ical expressivity of the syndrome is highly variable comprising more than 100 phenotypes, the DiGeorge syndrome, velocardiofacial syndrome, and conotruncal anomaly face syndrome being the most frequent. It is characterized mainly by facial anomalies, congenital cardiac defects, thymic and parathyroid hypoplasia or aplasia, resulting in T-cell immunodeficiency and hypocalcemia. Other common findings are velopharyngeal insufficiency, genito-urinary anomalies, learning difficulties, and psychiatric disorders. An early diagnosis of the syndrome is extremely important to assure all the necessary interventions for the different clinical aspects.

\section{Case Report}

A 12-month-old boy presented at our hospital with mucosal bleeding and diffuse skin petechiae. His previous clinical history revealed that he is the second child of healthy nonconsanguineous parents. Intrauterine growth retardation was noted during the second trimester of gestation. Neonatal seizures associated with an abnormal EEG occurred at day 2 of life. At the age of seven months, a Vgrade vesicoureteral reflux was diagnosed and surgical correction was performed. The baby was examined by the geneticist who asked for conventional cytogenetic analysis: the karyotype result was normal (46, XY). At four years of age he had three episodes of afebrile seizures. Magnetic resonance imaging showed a slight alteration of the focal frontal subcortical signal, interpreted as a possible outcome of perinatal hypoxic-ischemic insult.

At the clinical examination the boy was in a severe general condition, pale with scleral icterus. His liver was palpable $5 \mathrm{~cm}$ below the costal margin, and the spleen was enlarged, 1 $\mathrm{cm}$ below the costal margin. The laboratory assessment showed leukocyte counts of 14600 cells/ $\mu \mathrm{L}$, neutrophils 3400 cells/ $\mu \mathrm{L}$, lymphocytes 11060 cells/ $\mu \mathrm{L}$, hemoglobin $4.8 \mathrm{~g} / \mathrm{dL}$, platelets $10000 / \mu \mathrm{L}$, bilirubin $4.9 \mathrm{mg} / \mathrm{dL}$, all unconjugated. The direct Coombs' test was positive. Serum immunoglobulin levels were normal for his age (IgG $518 \mathrm{mg} / \mathrm{dL}$, IgA 87 $\mathrm{mg} / \mathrm{dL}$, IgM $116 \mathrm{mg} / \mathrm{dL})$. The child was treated with prednisone and intravenous immunoglobulin (IVIg) with complete resolution of symptoms. In the following years, recurrent episodes of bleeding associated with thrombocytopenia and other episodes of acute hemolysis occurred, and a chronic treatment with corticosteroids was employed; on one occasion a further IVIg treatment was necessary to recover a good platelet level. Because of the combination of immune thrombocytopenia and autoimmune hemolytic anemia, Evans syndrome was diagnosed. A recent study has demonstrated that numerous patients with Evans syndrome may have autoimmune lymphoprolipherative syndrome. ${ }^{3,4}$ Therefore, because of cytopenia, persistent hepatosplenomegaly, and the finding of cervical lymphadenopathy, FAS-mediated apoptosis was analyzed in our patient, despite the normal results. The number of $\mathrm{CD}^{+} \mathrm{CD} 4{ }^{-} \mathrm{CD} 8^{-}$ cells was never tested. Moreover, since the age of one year he has suffered from recurrent respiratory infections and frequent episodes of gastroenteritis.

When he was seven years old, he was admitted to our hospital because of one episode of fever, coughing, vomiting, and abdominal pain. A chest X-ray showed bronchopneumonia. Laboratory investigations were carried out and
Correspondence: Gloria Colarusso, Department of Paediatrics, Anna Meyer Children's Hospital, viale Pieraccini 24, 50139 Firenze, Italy.

E-mail: gloria.colarusso@yahoo.it

Key words: 22q11.2 deletion syndrome, Evans syndrome, DiGeorge syndrome, cytopenia, hypogammaglobulinemia.

Contributions: article conceived and designed by GC, EL; acquisition and interpretation of data by FT, EL, CA, TC, EG; article written by GC; critical appraisal by CA, EL, EG, TC, FL; final approval of article for publication by all authors.

Conflict of interest: the authors report no conflicts of interest.

Received for publication: 12 March 2010.

Revision received: 20 May 2010.

Accepted for publication: 25 May 2010.

This work is licensed under a Creative Commons Attribution 3.0 License (by-nc 3.0).

(C) Copyright G. Colarusso et al., 2010

Licensee PAGEPress, Italy

Pediatric Reports 2010; 2:e13

doi:10.4081/pr.2010.e13

showed low levels of $\gamma$-globulin on serum protein electrophoresis $(0.35 \mathrm{~g} / \mathrm{dL} ; 5.4 \%$, normal range: $7.7-17 \%$ ) with normal serum albumin (4.5 g/dL, 65.5\%). Immunoglobulin levels were tested and found to be impaired: IgG $283 \mathrm{mg} / \mathrm{dL}$ (age-related normal range: $625-1165 \mathrm{mg} / \mathrm{dL}$ ), IgA undetectable, and IgM $87 \mathrm{mg} / \mathrm{dL}$. The lymphocyte subsets (Table 1) showed slightly low $\mathrm{CD}^{+}$and $\mathrm{CD} 4^{+} \mathrm{T}$ cells, when compared to normal age values. Antibody responses to tetanus and to hemophilus $B$ antigens were poor (tetanus IgG $0.2 \mathrm{IU} / \mathrm{mL}$, hemophilus B IgG $2.5 \mathrm{mg} / \mathrm{L})$. Based on the finding of hypogammaglobulinemia with normal B cell number, common variable immunodeficiency was suspected initially and replacement therapy with intravenous immunoglobulin was started. A dose of $400 \mathrm{mg} / \mathrm{kg}$ was administrated every 28 days. Because of his clinical history, a second examination by a clinical geneticist was requested in February 2009: mild but significant facial abnormalities were noticed (narrow palpebral fissures, a slightly bulbous nose with hypoplastic nares, large and low-set ears), and a 22q11. DS was clinically suspected and then confirmed by FISH analysis. Therefore a diagnosis of partial DiGeorge syndrome was made.

Consequently, a cardiological evaluation was performed and no congenital heart defect was found. The ENT evaluation showed slight velopharyngeal insufficiency that justified his nasal speech. Bone mass and metabolism were normal (ionized and total calcium, phosphate, parathyroid hormone, 25-hydroxyvitamin D, 
Table 1. Lymphocyte subsets - absolute number.

\begin{tabular}{lcc}
\hline Lymphocytes & Patient (cells/pL) & Age-related normal value (cells/pL) \\
${\mathrm{CD} 19^{+}}^{+}$ & 517 & $300-700$ \\
$\mathrm{CD}^{+}$ & 1053 & $1100-2800$ \\
\hline $\mathrm{CD}^{+}{ }^{+} \mathrm{CD} 4^{+}$ & 574 & $500-1800$ \\
$\mathrm{CD}^{+}{ }^{+} \mathrm{CD}{ }^{+}$ & 398 & $400-1200$ \\
\hline $\mathrm{CD}{ }^{-} \mathrm{CD} 16^{+} \mathrm{CD} 56^{+}$ & 149 & $100-600$ \\
$\mathrm{CD} 4 / \mathrm{CD} 8$ & 1.4 & $1.4-2.7$ \\
\hline
\end{tabular}

1,25-dihydroxyvitamin D, serum osteocalcin levels, urinary deoxipyridinoline concentration, and dual energy X-ray absorptiometry were evaluated). Neonatal hypocalcemia was never detected, and titanic seizures or tremori were never shown. Besides immunological and hematological follow-up, an educational assessment was performed and the child was introduced to a neuropsychological follow-up.

\section{Discussion}

The immunodeficiency arises as a consequence of thymic hypoplasia in patients with the deletion syndrome. Patients with a complete absence of the thymus ("complete" DiGeorge syndrome) exhibit severe T-cell immunodeficiency with a severe combined immunodeficiency phenotype requiring immune reconstitution by bone marrow transplantation or thymic transplantation..$^{5-7}$ However, "complete" DiGeorge syndrome accounts for $<1 \%$ of patients. ${ }^{8,9}$ The majority of patients with 22q11.2 DS and immune defects exhibit mild to moderate deficits in T-cell numbers (so-called "partial" DiGeorge syndrome). Studies of humoral deficiencies in 22q11.2 DS patients have yielded conflicting results..$^{9-12}$ Evidence of partial antibody deficiency (IgA deficiency, IgM deficiency, IgG subclass deficiency, specific antibody deficiency, or specific antibody responses to pneumococcal polysaccharide antigen) has been reported rarely, ${ }^{11,13,14}$ but no mention of a deficiency of almost two classes of antibodies associated with chromosome 22q11.2 DS is found in the literature.

In the $22 q 11.2 \mathrm{DS}$, autoimmune disease may occur in up to $30 \%$ of patients and includes autoimmune cytopenias, autoimmune endocrinopathies, and autoimmune arthritis. ${ }^{15-18}$ Previous studies reported cases of autoimmune hemolytic anemia and immune thrombocytopenia, but only a few patients with Evans syndrome have been described..$^{15,16,19-21}$ To the best of our knowledge, the association of Evans syndrome, hypogammaglobulinemia, and 22q11.2 DS has not been reported before.

Early diagnosis of $22 \mathrm{q} 11.2 \mathrm{DS}$ is extremely important for early evaluation of all the clinical and functional aspects of the syndrome (endocrine, immunological, cardiac, neuropsychiatric, etc.), so as to begin a prompt therapeutic program. We concluded that hematologists should consider the possibility of the 22q11.2 DS in children of all ages who present with Evans syndrome associated with hypogammaglobulinemia and mild facial anomalies.

\section{References}

1. Wren C, Scambler PJ, Wilson DI, et al. Minimum prevalence of chromosome 22q11 deletions. Hum Mol Genet 1994;4: 31-6.

2. Carlson C, Sirotkin H, Pandita R, et al. Molecular definition of 22q11 deletions in 151 velo-cardio-facial syndrome patients. Am J Hum Genet 1997;61:620-9.

3. Teachey DT, Manno CS, Axsom KM, et al. Unmasking Evans syndrome: T-cell phenotype and apoptotic response reveal autoimmune lymphoprolipherative syndrome (ALPS). Blood 2005;105:2443-8.

4. Seif AE, Manno CS, Sheen C, et al. Identifying autoimmune lymphoproliferative syndrome in children with Evans syndrome: a multi-institutional study. Blood 2010;115:2142-5.

5. Land MH, Garcia-Lloret MI, Borzy MS, et al. Long-term results of bone marrow transplantation in complete DiGeorge syndrome. J Allergy Clin Immunol 2007;120: 908-15.

6. Markert ML, Devlin BH, Alexieff MJ, et al. Review of 54 patients with complete DiGeorge anomaly enrolled in protocols for thymus transplantation: outcome of 44 consecutive transplants. Blood 2007;109: 4539-47.

7. Markert ML, Devlin BH, Chinn IK, et al. Thymus transplantation in complete DiGeorge anomaly. Immunol Res 2009;44: 61-70.

8. Ryan AK, Goodship JA, Wilson DI, et al. Spectrum of clinical features associated with interstitial chromosome $22 q 11$ deletions: a European collaborative study. J
Med Genet 1997;34:798-804.

9. McDonald-McGinn DM, Kirschner R, Goldmuntz E, et al. The Philadelphia story: 22q11.2 deletion: report on 250 patients. Genet Couns 1999;10:11-24.

10. Junker AK, Driscoll DA. Humoral immun ity in DiGeorge syndrome. J Pediatr 1995; 127:231-7.

11. Smith CA, Driscoll DA, Emanuel BS, et al. Increased prevalence of immunoglobulin A deficiency in patients with the chromosome 22q11.2 deletion syndrome (DiGeorge syndrome/velocardiofacial syndrome). Clin Diagn Lab Immunol 1998;5: 415-7.

12. Gennery AR, Barge D, O'Sullivan JJ, et al. Antibody deficiency and autoimmunity in $22 q 11.2$ deletion syndrome. Arch Dis Child 2002;86:422-5.

13. Finocchi A, Di Cesare S, Romiti ML, et al. Humoral immune responses and CD27+ B cells in children with DiGeorge syndrome (22q11.2 deletion syndrome). Pediatr Allergy Immunol 2006;17:382-8.

14. Jawad AF, McDonald-McGinn DM, Zackai $\mathrm{E}$, et al. Immunologic features of chromosome 22q11.2 deletion syndrome (DiGeorge syndrome/velocardiofacial syndrome). J Pediatr 2001;139:715-23.

15. Davies JK, Telfer P, Cavenagh JD, et al. Autoimmune cytopenias in the $22 q 11.2$ deletion syndrome. Clin Lab Haematol 2003;25:195-7.

16. Sakamoto 0, Imaizumi M, Suzuki A, et al. Refractory autoimmune hemolytic anemia in a patient with chromosome $22 q 11.2$ deletion syndrome. Pediatr Int 2004;46: 612-4.

17. Sullivan KE, McDonald-McGinn DM, Driscoll DA, et al. Juvenile rheumatoid arthritis-like polyarthritis in chromosome $22 q 11.2$ deletion syndrome (DiGeorge anomalad/velocardiofacial syndrome/ conotruncal anomaly face syndrome). Arthritis Rheum 1997;40:430-6.

18. Brown JJ, Datta V, Browning MJ, et al. Graves' disease in DiGeorge syndrome: patient report with a review of endocrine autoimmunity associated with 22q11.2 deletion. J Pediatr Endocrinol Metab 2004;17:1575-9.

19. Lawrence S, Mc Donald-McGinn DM, Zackai E, et al. Thrombocytopenia in patients with chromosome $22 q 11.2$ deletion syndrome. J Pediatr 2003;143:277-8.

20. Bruno B, Barbier C, Lambilliotte A, et al. Auto-immune pancytopenia in a child with DiGeorge sindrome. Eur J Pediatr 2002; 161:390-2.

21. Kratz CP, Niehues T, Lyding S, et al. Evans syndrome in a patient with chromosome 22q11.2 deletion syndrome: a case report. Pediatr Hematol Oncol 2003;20:167-72. 